\title{
Marco normativo e indicadores de las bibliotecas públicas de México y Colombia
}

\author{
Federico Hernández Pacheco *
}

Artículo recibido: 19 de septiembre de 2012.

Artículo aceptado: 10 de octubre de 2012.

\section{RESUMEN}

Se presentan los resultados de una investigación exploratoria a través de un estudio comparado para conocer la situación de las bibliotecas públicas en México y Colombia. Se exponen los antecedentes y el marco conceptual, los comparativos de datos sociodemográficos, legales y normativos, las estructuras bibliotecarias y la información de estadísticas e indicadores generados en cada uno de estos países. Además, se considera una propuesta del Programa Iberoamericano de Cooperación en Bibliotecas Públicas (PICBIP) para un sistema de indicadores de gestión mínimos para las bibliotecas públicas de Iberoamérica, se presentan conclusiones de este estudio y recomendaciones sobre las líneas de investigación a seguir.

* Instituto de Investigaciones Bibliotecológicas y de la Información de la UNAM, México. federicohp@iibi.unam.mx

INVESTIGACIÓN BiBLIOTECOLÓGICA, Vol. 26, Núm. 58, septiembre/diciembre, 2012, México, ISSN: 0187-358X. pp. 215-233 
Palabras clave: Bibliotecas públicas; México; Colombia; Marco normativo; Indicadores de gestión.

\section{ABSTRACT}

Legal framework and indicators for public libraries in Mexico and Colombia

Federico Hernández Pacheco

A report of the results of a comparative study of public libraries in Mexico and Colombia is provided in this paper, which examines the respective backgrounds and operative rules; legal and theoretical frameworks, as well as the statistical indicators of the libraries in each country. The paper also examines the minimal management indicators for public libraries developed by the Iberian-American Program for Cooperation in Public Libraries (PICBIP, by its Spanish acronym ), followed by conclusions and recommendation for further research.

Keywords: Public libraries; Mexico; Colombia; Rules frame; Management indicators.

\section{INTRODUCCIÓN}

L a presencia de la biblioteca pública en América Latina es una realidad de las distintas situaciones sociales, culturales, economicas políticas en que de las distintas situaciones sociales, culturales, económicas y políticas en que se encuentran inmersos los países de la región.

Anualmente se realizan encuentros nacionales e internacionales de bibliotecas públicas donde se escuchan los desarrollos alcanzados en Argentina, Colombia y México, así como de todos los países que se encuentran representados. Éstos tratan sobre la naturaleza de la biblioteca pública, sus logros y problemas, las nuevas tecnologías y la brecha digital, la lectura y los nuevos soportes de información, los servicios, los recursos humanos, y sobre los distintos modelos de biblioteca pública que se vienen ensayando.

Entre los países que han tenido notoriedad en la última década en materia de bibliotecas públicas están Chile, México y Colombia, mismos que se han sido reconocidos por la Fundación Bill y Melinda Gates, además de que han recibido de ésta financiamientos para la realización de importantes proyectos bibliotecarios. 
De esta manera con el ánimo de conocer más sobre los emprendimientos que se vienen realizando en la región, nos avocamos a realizar un estudio comparado entre las bibliotecas públicas de México y Colombia con la finalidad de identificar la normatividad y los sistemas de indicadores de gestión utilizados, y considerar una plataforma común de indicadores que pudiera aplicarse a las bibliotecas públicas latinoamericanas para posibilitar la obtención de datos que sirvan de base para posteriores investigaciones.

A continuación presentamos los resultados de este estudio realizado a partir de la revisión de los antecedentes y el marco conceptual, seguido del análisis conjunto de los datos socio-demográficos, legales y normativos, las estructuras bibliotecarias y la información generada en cada uno de estos países. Asimismo revisamos algunas acciones que apuntan a una propuesta de sistema de indicadores mínimos para las bibliotecas públicas de Iberoamérica, y terminamos presentando nuestras conclusiones y las recomendaciones de líneas de investigación necesarias.

\section{ANTECEDENTES Y MARCO CONCEPTUAL}

La biblioteca pública, entendida como una institución de carácter social, tiene un precedente histórico que abarca diversas circunstancias y momentos en todo el mundo. Así, desde finales del siglo XVIII las bibliotecas públicas han sido parte de la infraestructura educativa y cultural en muchos países. Desde entonces han ayudado al reforzamiento de la enseñanza y la lectura, han favorecido los niveles educativos de las poblaciones, han sido espacios idóneos para el esparcimiento cultural y recreativo y, sobre todo, han sido instancias que dan solución a problemas y a necesidades de información. Todo esto a partir de las acciones de algunos gobiernos que le han dado un papel protagónico a las bibliotecas públicas.

Sin embargo dichas acciones no han sido casuales, ya que han tenido sus inicios en los planteamientos de la Conferencia Intergubernamental sobre la Planificación de las Infraestructuras Nacionales de Documentación, Bibliotecas y Archivos, realizada en París en 1974, con la colaboración de la UNESCO, la FID (International Federation of Documentacion), la IFLA (International Federation of Library Association) y la ICA (Internal Coucil of Archives), ${ }^{1}$ que puede considerarse de vanguardia en la transformación de las bibliotecas, incluyendo las públicas y sus redes de información y servicios en todo el mundo.

1 Cf. Victoria Oliver, (s. d.), El papel de las bibliotecas en los sistemas nacionales de información cientifica, localizado: 2 sept. 2012, en http://dialnet.unirioja. es/servlet/fichero_articulo?codigo=967403 
Desde esa Conferencia han surgido otras aportaciones importantes que han dado un nuevo rumbo al desarrollo de las bibliotecas. Tal es el caso del Manifiesto de la UNESCO sobre biblioteca pública de 1994; la Declaración de Copenhague, promulgada en 1999; la Declaración de Caracas sobre la Biblioteca Pública promulgada en 1999; las Directrices IFLA/UNESCO para el desarrollo de servicios de bibliotecas públicas de 2001; la declaración de Glasgow sobre las Bibliotecas, Servicios de Información y Libertad Intelectual de 2002; el Manifiesto de Oeiras de 2003; y el Manifiesto de Alejandría sobre Bibliotecas de 2005.

Éstos y otros documentos tienen la particularidad de considerar a la biblioteca, y sobre todo a la biblioteca pública, como un factor de desarrollo e instrumento de cambio social, y por ello, capaz de incidir en la vida de las sociedades en las que se encuentra. De ahí el interés y el apoyo por parte de gobiernos y diversas instancias privadas para desarrollar infraestructuras bibliotecarias, y para incrementar y modernizar todos los servicios que se brindan. $^{2}$

Mucho se ha escrito sobre la pertinencia de desarrollar sistemas de bibliotecas públicas en los países en vías de desarrollo, pues como señalan la UNESCO y la IFLA

las unidades de información de libre acceso desempeñan un papel importante en el progreso y mantenimiento de una sociedad democrática, al ofrecer a cada persona acceso a toda una serie de conocimientos, ideas y opiniones. ${ }^{3}$

Las bibliotecas públicas han sido definidas según los momentos históricos, marcos geográficos, políticos y legales, necesidades e impactos sociales, variedad y oferta de servicios, entornos tecnológicos, etcétera. Por ejemplo, una definición que da la UNESCO de 1972, aún con fuerza y vigencia, es la siguiente:

La biblioteca pública es una institución democrática para la enseñanza, la cultura y la información. Es el principal medio para dar a todo el mundo libre acceso a la suma de los pensamientos y de las ideas del hombre y a las expresiones de su imaginación creativa. La biblioteca pública como fuerza viva al servicio de la

2 Cf. Federico Hernández Pacheco (2011), La Biblioteca Vasconcelos: un nuevo modelo de biblioteca pública en México, Trabajo presentado en el $7^{\circ}$ Seminario Hispanomexicano en Biblioteconomía y Documentación, México: UNAM, CUIB, disponible en: http://cuib.unam.mx/

3 Philip Gill (2007), Directrices IFLA/Unesco para el desarrollo del servicio de bibliotecas públicas, $2^{a}$ ed. México: CNCA/DGB, p. 26. 
enseñanza, la cultura y la información y como instrumento indispensable para el fomento de la paz y la comprensión entre las personas y entre las naciones. ${ }^{4}$

Otra definición de la misma UNESCO, y que va acorde con la sociedad de la información y del conocimiento que actualmente vivimos, considera a la biblioteca pública como un centro de información que facilita a los usuarios todo tipo de datos y conocimientos, y que presta sus servicios sobre la base de la igualdad de acceso a todas las personas, independientemente de su edad, raza, sexo, religión nacionalidad, idioma o condición social. ${ }^{5}$

Asimismo, el Manifiesto IFLA-UNESCO de 2002 define a la biblioteca pública como

una organización establecida, respaldada y financiada por la comunidad, ya sea por conducto de una autoridad u órgano local, regional o nacional, o mediante cualquier otra forma de organización colectiva. Brinda acceso al conocimiento, a la información y al trabajo intelectual a través de una serie de recursos y servicios y está a disposición de todos los miembros de la comunidad en igualdad de condiciones, sin distinción de raza, nacionalidad, edad, sexo, religión, idioma, discapacidad, condición económica y laboral y nivel de escolaridad. ${ }^{6}$

En este contexto, el grupo de investigación sobre biblioteca pública de la Escuela Interamericana de Bibliotecología de la Universidad de Antioquia da la siguiente definición precisa y de grandes dimensiones o alcances:

la biblioteca pública es una institución de carácter social y cultural, financiada y reglamentada por el Estado, cuya finalidad es posibilitar el libre acceso a la información registrada en un soporte documental y que responde a unos criterios de selección y adquisición para la satisfacción de necesidades en el plano educativo, informativo, cultural y de uso del tiempo libre; busca con ello contribuir al mejoramiento de la calidad de vida de todas las personas que hacen parte de una comunidad en un entorno (municipio, vereda o barrio) para la construcción y articulación de relaciones democráticas, por medio de servicios y programas gratuitos y coordinados por un bibliotecario. ${ }^{7}$

Sin duda ésta es una definición que invita a la reflexión.

4 Orlanda Jaramillo, Mónica Montoya Ríos y Alejandro Uribe Tirado, (2008), Biblioteca Pública: su gestión en el contexto de la sociedad de la información, Buenos Aires: Alfagrama, p. 155.

5 Ibid.p. 156.

6 Op. cit. Philip Gill (2007), p. 26.

7 Op. cit. Orlanda Jaramillo, p. 157. 
Como podemos observar la biblioteca pública tiene diversas vertientes que comparten una responsabilidad social, como son los apoyos que brindan el Estado, los gobiernos y múltiples instancias públicas y privadas; el respaldo de los habitantes de una región o comunidad; la diversidad e igualdad en el acceso a los servicios que otorga; la satisfacción de necesidades principalmente educativas y culturales; los espacios recreativos y de intercambio de opiniones, ideas y conocimientos; así como las áreas tecnológicas o lúdicas. Dichas vertientes la proyectan hoy por hoy como una institución actual y necesaria para todos los seres humanos.

Por esta razón, comparar las características o vertientes de las bibliotecas públicas se torna necesario para generar proyectos y actuar a través de un intercambio de experiencias que dé como resultado la aplicación de las mejores prácticas en una o más regiones en igualdad de condiciones.

Comparar, según la Real Academia de la Lengua, es "fijar la atención entre dos o más objetos para descubrir sus relaciones o estimar sus diferencias o semejanzas" ${ }^{8}$ El método comparativo, nos dice Olivera, consiste precisamente en procurar el avance del conocimiento mediante el examen simultáneo de las semejanzas y diferencias entre las áreas u objetos que se quieren conocer. La comparación, abunda, permite plantear los problemas por investigar, analizarlos, y comprobar la validez de las respuestas o soluciones. Y no brota simplemente de los hechos, supone una sistematización de las diferentes variables a estudiar. ${ }^{9}$

De esta forma, a través de la comparación de algunos datos socio-demográficos y de los marcos legislativo y normativo, así como de la información generada en cada país, podremos conocer las semejanzas y diferencias de las bibliotecas públicas de dos países y generar nuevo conocimiento en esta área de la bibliotecología.

\section{COMPARATIVO SOCIO-DEMOGRÁFICO ${ }^{10}$}

México y Colombia son países multiculturales que comparten su condición de países latinoamericanos, hablantes de español y que definieron su carácter y soberanía nacional en el siglo XIX, luego de un largo período colonial como parte del imperio español.

8 Real Academia Española (2001), disponible en: http://www.rae.es/rae.html

9 Carlos Olivera Lahore (1986), Introducción a la educación comparada. San José: Universidad Estatal a Distancia, p. 260.

10 Datos tomados del Instituto Nacional de Estadística Geografía e Informática. Localizado: 2 sept, 2012, en http://www.inegi.org.mx; y del Departamento Administrativo Nacional de Estadística, Localizado: 2 sept. 2012, en: http://www.dane.gov.co. 
Ambos países tiene una organización política basada en la práctica de la democracia, siendo México una república constitucional federada, mientras que Colombia es una república unitaria descentralizada.

La superficie territorial de México es de un millón 964 mil 375 kilómetros cuadrados. Colinda al Norte con los Estados Unidos de América, al Oeste y Sur con el océano Pacífico y al Sureste con Guatemala, Belice y el Mar Caribe. Al Este limita con el Golfo de México.

Colombia tiene un territorio que abarca un millón 141 mil 748 kilómetros cuadrados. Limita al Este con Venezuela y Brasil, al Sur con Perú y Ecuador, al Noroeste con Panamá, al Norte con el Mar Caribe y al Oeste con el océano Pacífico. Es la única nación sudamericana que tiene salida a dos bloques de mar distintos.

La población actual de México es de 112 millones 336 mil 538 habitantes. En Colombia, hay 46 millones 745 mil 601 habitantes.

\section{Comparativo Legal y NORMATivo}

En México existe una ley que condiciona y afecta el desempeño de las bibliotecas públicas: La Ley general de bibliotecas (LGB). En Colombia se tiene la Ley No. 1379 por la cual se organiza la Red Nacional de Bibliotecas Públicas (LBP).

La LGB mexicana fue decretada en 1988, y fue reformada en el año 2009. Sin embargo, no ha sido reglamentada. En contraparte, la LBP colombiana fue promulgada en el año 2010 y cuenta con una reglamentación parcial emitida el mismo año. ${ }^{11}$

Ambos países han instrumentado la creación y el desarrollo de redes nacionales de bibliotecas públicas, cuyas características y componentes quedan descritos en sus respectivas leyes. ${ }^{12}$

En la Tabla 1 mostramos algunas de sus facetas más notables:

11 Decreto No. 2907 de 2010 por el cual se reglamenta parcialmente la ley 1379 de 2012 sobre la Red Nacional de Bibliotecas Públicas, Localizado: 2 sept. 2012, en: http:/www.alcaldiabogota.gov.co/sisjur/normas/Norma1.jsp? $\mathrm{i}=40115$

12 Debe notarse que la Red Nacional de Bibliotecas Públicas de Colombia se comenzó a conformar desde los años 90 del siglo pasado. En la Ley 397, conocida como la Ley general de la cultura, en su artículo se prescribe la consolidación, el desarrollo y la coordinación de esta red, Cf Ley general de la cultura, localizado: 2 sept. 2012, en: http://www.enredartepanama.org/site. 
Tabla 1

\begin{tabular}{|c|c|c|}
\hline Concepto & México & Colombia \\
\hline $\begin{array}{l}\text { Objeto de la ley } \\
\text { bibliotecaria }\end{array}$ & $\begin{array}{l}\text { I. La distribución y coordinación entre los } \\
\text { Gobiernos Federal, Estatales y Munici- } \\
\text { pales de la función educativa y cultural } \\
\text { que se lleva a cabo mediante el esta- } \\
\text { blecimiento, sostenimiento y organiza- } \\
\text { ción de bibliotecas públicas; } \\
\text { II. El señalamiento de las normas básicas } \\
\text { para la configuración de la Red Nacio- } \\
\text { nal de Bibliotecas Públicas; } \\
\text { III. El establecimiento de las bases y direc- } \\
\text { trices para la integración y el desarrollo } \\
\text { de un Sistema Nacional de Bibliotecas } \\
\text { y; } \\
\text { IV. La determinación de lineamientos para } \\
\text { Ilevar a cabo la concertación con los } \\
\text { sectores social y privado en esta mate- } \\
\text { ria. }\end{array}$ & $\begin{array}{l}\text { Definir la política de la Red Nacional de } \\
\text { Bibliotecas Públicas, regular su funciona- } \\
\text { miento y establecer los instrumentos para } \\
\text { su desarrollo integral y sostenible. }\end{array}$ \\
\hline $\begin{array}{l}\text { Definición de la } \\
\text { biblioteca pública }\end{array}$ & $\begin{array}{l}\text { Todo establecimiento que contenga un } \\
\text { acervo impreso o digital de carácter gene- } \\
\text { ral superior a quinientos títulos, cataloga- } \\
\text { dos y clasificados, y que se encuentre des- } \\
\text { tinado a atender en forma gratuita a toda } \\
\text { persona que solicite la consulta o préstamo } \\
\text { del acervo en los términos de las normas } \\
\text { administrativas aplicables. }\end{array}$ & $\begin{array}{l}\text { Es aquella que presta servicios al público } \\
\text { en general, por lo que está a disposición } \\
\text { de todos los miembros de la comunidad por } \\
\text { igual, sin distinción de raza, nacionalidad, } \\
\text { edad, sexo, religión, idioma, discapacidad, } \\
\text { condición económica y laboral o nivel de } \\
\text { instrucción. }\end{array}$ \\
\hline $\begin{array}{l}\text { Composición de } \\
\text { la Red }\end{array}$ & $\begin{array}{l}\text { Se integra la Red Nacional de Bibliotecas } \\
\text { Públicas con todas aquéllas constituidas y } \\
\text { en operación dependientes de la Secretaría } \\
\text { de Educación Pública y aquéllas creadas } \\
\text { conforme a los acuerdos o convenios de } \\
\text { coordinación celebrados por el Ejecutivo } \\
\text { Federal, por conducto de la Secretaría de } \\
\text { Educación Pública con los Gobiernos de } \\
\text { los Estados y del Departamento del Distrito } \\
\text { Federal. }\end{array}$ & $\begin{array}{l}\text { La Red Nacional de Bibliotecas } \\
\text { Públicas articula e integra las bibliotecas } \\
\text { públicas estatales y sus servicios bibliote- } \\
\text { carios en el orden nacional, departamental, } \\
\text { distrital y municipal. }\end{array}$ \\
\hline $\begin{array}{l}\text { Coordinación de } \\
\text { la Red }\end{array}$ & $\begin{array}{l}\text { Corresponde a la Secretaría de Educación } \\
\text { Pública proponer, ejecutar y evaluar la po- } \\
\text { lítica nacional de bibliotecas atendiendo al } \\
\text { Plan Nacional de Desarrollo y programas } \\
\text { correspondientes. } \\
\text { Corresponde a la Secretaría de Educación } \\
\text { Pública: } \\
\text { I. Efectuar la coordinación de la Red. }\end{array}$ & $\begin{array}{l}\text { La coordinación de la Red Nacional de Bi- } \\
\text { bliotecas Públicas está a cargo del Ministe- } \\
\text { rio de Cultura por intermedio de la Bibliote- } \\
\text { ca Nacional de Colombia. }\end{array}$ \\
\hline $\begin{array}{l}\text { Participación en } \\
\text { la Red }\end{array}$ & $\begin{array}{l}\text { Los Gobiernos, Federal, Estatales y Mu- } \\
\text { nicipales, dentro de sus respectivas juris- } \\
\text { dicciones, promoverán el establecimiento, } \\
\text { organización y sostenimiento de bibliotecas } \\
\text { públicas, impulsando el establecimiento, }\end{array}$ & $\begin{array}{l}\text { Esta ley se aplica a las instituciones, enti- } \\
\text { dades, procesos y recursos relativos a la } \\
\text { Red Nacional de Bibliotecas Públicas coor- } \\
\text { dinada por el Ministerio de Cultura-Bibliote- } \\
\text { ca Nacional de Colombia. }\end{array}$ \\
\hline
\end{tabular}




\begin{tabular}{|c|c|c|}
\hline & $\begin{array}{l}\text { equipamiento, mantenimiento y actualización } \\
\text { permanente de un área de servicios de cóm- } \\
\text { puto y los servicios culturales complementa- } \\
\text { rios que a través de éstas se otorguen. } \\
\text { Las bibliotecas pertenecientes a los secto- } \\
\text { res social y privado que presten servicios } \\
\text { con características de biblioteca pública } \\
\text { en los términos de la presente ley y que } \\
\text { manifiesten su disposición a incorporarse } \\
\text { a la Red Nacional de Bibliotecas Públicas, } \\
\text { celebrarán con la Secretaría de Educación } \\
\text { Pública o con los Gobiernos de los Estados, } \\
\text { según sea el caso, el correspondiente com- } \\
\text { promiso de adhesión. }\end{array}$ & $\begin{array}{l}\text { Las disposiciones de esta ley no son de } \\
\text { aplicación a la red de bibliotecas del Banco } \\
\text { de la República, ni de las cajas de compen- } \\
\text { sación,... ni, en general, a ninguna otra } \\
\text { biblioteca ni sistema bibliotecario que no } \\
\text { haga parte de !a Red Nacional de Bibliote- } \\
\text { cas Públicas. } \\
\text { Asimismo, impulsará su articulación con } \\
\text { otras redes bibliotecarias del país de carác- } \\
\text { ter mixto o privado, mediante el estableci- } \\
\text { miento de relaciones voluntarias de coope- } \\
\text { ración y complementariedad, sin perjuicio } \\
\text { de la aplicación de su respectiva normativa. }\end{array}$ \\
\hline $\begin{array}{l}\text { Inclusión de } \\
\text { órganos } \\
\text { colegiados } \\
\text { de apoyo }\end{array}$ & $\begin{array}{l}\text { Se crea el Consejo de la Red Nacional de } \\
\text { Bibliotecas Públicas con carácter de órga- } \\
\text { no consultivo, el que a solicitud expresa lle- } \\
\text { vará a cabo las siguientes acciones: } \\
\text { I. Presentar propuestas para mejorar los } \\
\text { servicios que prestan las bibliotecas } \\
\text { integrantes de la Red; y } \\
\text { II. Formular recomendaciones para lograr } \\
\text { una mayor participación de los sec- } \\
\text { tores social y privado, comunidades y } \\
\text { personas interesadas en el desarrollo } \\
\text { de la Red. }\end{array}$ & $\begin{array}{l}\text { Créase el Comité Técnico Nacional de Bi- } \\
\text { bliotecas Públicas como organismo asesor } \\
\text { del Ministerio de Cultura, para la coordina- } \\
\text { ción e impulso del desarrollo de la Red Na- } \\
\text { cional de Bibliotecas } \\
\text { Públicas. } \\
\text { Son funciones del Comité Técnico Nacional } \\
\text { de Bibliotecas } \\
\text { Públicas las siguientes: } \\
\text { 1. Actuar como instancia de articulación y } \\
\text { concertación con el Ministerio de Cul- } \\
\text { tura y las instituciones de! sector pú- } \\
\text { blico, privado o personas naturales que } \\
\text { puedan contribuir al desarrollo de la } \\
\text { Red Nacional de Bibliotecas Públicas. } \\
\text { 2. Diseñar mecanismos de cooperación } \\
\text { entre la Red Nacional de Bibliotecas } \\
\text { Públicas y otras redes bibliotecarias } \\
\text { públicas, mixtas, privadas y comunita- } \\
\text { rias. } \\
\text { 3. Asesorar al Ministerio de Cultura, a la } \\
\text { Biblioteca Nacional y a otras entidades } \\
\text { públicas, en la definición de lineamien- } \\
\text { tos, criterios y normas relativas a las } \\
\text { bibliotecas públicas y el fomento a la } \\
\text { lectura, así como a los demás asuntos } \\
\text { relacionados con los temas de que tra- } \\
\text { tura, escritura, uso de las bibliotecas, } \\
\text { desarrollos tecnológicos, relaciones de } \\
\text { otros temas afines. }\end{array}$ \\
\hline
\end{tabular}

Fuente: Ley general de bibliotecas, localizado 2 sept. 2012, en: http://www.diputados.gob.mx/Leyes Biblio/pdf/134.pdf, Ley No. 1379 por la cual se organiza la Red Nacional de Bibliotecas Públicas... Localizado 2 sept. 2012, en: http://www.ascolbi.org/documentos/Ley_1379_2010_Bibliotecas.pdf 
Notamos en primer lugar que el objeto de ambas leyes muestra distinciones, pues en México la legislación declara políticas que prescriben acciones de coordinación y normativas que aplican a los tres órdenes de gobierno, así como a los sectores social y privado, en tanto que el objeto de la ley colombiana se centra en tres acciones: definir la política, regularla e instrumentarla de manera integral y sostenible.

Vemos así que en ambas legislaciones el objeto define el alcance de la política, lo cual también presenta diferencias, pues la ley mexicana incluye también la creación del Sistema Nacional de Bibliotecas, en tanto que la ley colombiana sólo trata sobre la Red Nacional de Bibliotecas Públicas.

La forma como ambas leyes conciben la biblioteca pública también es evidencia de desigualdad, pues en México se enfatiza en su definición el acervo y la atención gratuita y conforme a normas, mientras que en Colombia se pone el acento en los servicios al público. Asimismo, tenemos que la biblioteca pública en México atiende a toda persona que solicita la consulta o préstamo del acervo, en tanto que en Colombia se da el servicio a todos los miembros de la comunidad sin distinción.

En su composición, las redes de bibliotecas públicas de ambos países tienen una integración similar y acorde a las divisiones políticas de sus territorios. No obstante, la forma de organización difiere por el modo como se contempla la aplicación de la legislación, pues en México hay bibliotecas públicas dependientes de la Secretaría de Educación Pública y otras creadas a partir de acuerdos con los estados. En Colombia, las bibliotecas públicas son un asunto de Estado que obliga a todos los niveles de gobierno a participar.

Otra característica diferencial de la organización tiene que ver con la coordinación de las redes de bibliotecas públicas, que en México le corresponde a la Secretaría de Educación Pública, y en Colombia la lleva el Ministerio de Cultura, a través de la Biblioteca Nacional. En el modelo mexicano, las responsabilidades se reparten entre los gobiernos federal, estatales y municipales, mientras que en Colombia todas las bibliotecas públicas de la Red Nacional dependen del ministerio que funge como coordinador.

La existencia de bibliotecas públicas que no son administradas por agencias gubernamentales es considerada de forma diferente en ambos países. Así en México esas bibliotecas se pueden incorporar a la Red Nacional de Bibliotecas Públicas, en tanto que en Colombia se contempla la articulación a través de relaciones voluntarias de cooperación o complementariedad.

Ambas redes deben contar con órganos colegiados de apoyo conforme las legislaciones. No obstante, en México ese órgano debe tener un carácter consultivo y en Colombia es un organismo asesor para la coordinación y el impulso de la red. 
Tenemos entonces que hay señaladas diferencias entre las redes de bibliotecas públicas de ambos países, como puede apreciarse en esta comparación de los instrumentos legales que están vigentes. Estas distinciones son de carácter (objeto de la ley, definición de la biblioteca pública) y de organización (composición, coordinación, participación, inclusión de órganos colegiados de apoyo).

Es importante agregar que para ambas redes bibliotecarias se han generado gran cantidad de instrumentos normativos destinados a la capacitación de los recursos humanos y para la instalación y el mantenimiento de los servicios. Además, en el caso de Colombia, la Universidad de Antioquia se ha involucrado activamente en la generación de la bibliografía, documentos y proyectos requeridos.

\section{COMPARATIVO DE LAS ESTRUCTURAS BIBLIOTECARIAS ${ }^{13}$}

En México hay 7, 320 bibliotecas públicas, lo cual se traduce a que en promedio se tiene una de estas instituciones por cada 15,347 habitantes. No obstante, la división política municipal no es homogénea para todos los estados, además de que las estructuras bibliotecarias estatales son diferentes. La cobertura de la Red Nacional de Bibliotecas Públicas es del 93 por ciento del país.

En Colombia, la Red Nacional agrupa 1,498 bibliotecas públicas en el territorio, que son administradas por instituciones oficiales o privadas. ${ }^{14} \mathrm{Al}$ igual que en México, en Colombia se encuentran sobradas diferencias en las bibliotecas ocasionadas por la división política departamental-municipal. Tenemos un estimado de una biblioteca pública por cada 31,205 habitantes y además notamos que hay una cobertura del 97 por ciento de los departamentos que integran el país que tienen servicios bibliotecarios públicos.

Por otra parte existen diferencias entre los países en materia de los actores involucrados en el establecimiento y el desarrollo de las bibliotecas públicas. De esta manera en México la historia pone en evidencia un compromiso gubernamental continuo para crear y mantener bibliotecas públicas, sobre todo a partir de la etapa posrevolucionaria del siglo XX, dejándole un papel menor o nulo a la participación privada.

13 Los datos cuantitativos que se reportan cuando no tienen una cita resultaron de cálculos realizados sobre la información demográfica, geográfica y bibliotecaria disponibles.

14 Jeimy Hernández Toscano (2009), La Red Nacional de Bibliotecas Públicas, 6 h. Localizado: 2 sept, 2012, en: http://www.cerlalc.org/redplanes/boletin_redplanes2/imagenes/documentos/2_Red_bibliotecas.pdf, p. 6. 
En Colombia tenemos el caso del departamento de Antioquia, y en particular del municipio de Medellín, en donde durante el mismo periodo se ha dado por igual la intervención privada y la estatal. En este caso, en alianza con el Estado han colaborado la iglesia y los intelectuales, las instituciones de asistencia social y cívica, la empresa privada y las organizaciones comunitarias o populares. ${ }^{15}$

Los aspectos organizativos (Tabla 2) que podemos comparar son los siguientes:

Tabla 2

\begin{tabular}{|l|l|l|}
\hline \multicolumn{1}{|c|}{ Concepto } & \multicolumn{1}{|c|}{ México } & \multicolumn{1}{|c|}{ Colombia } \\
\hline $\begin{array}{l}\text { Por entidad del } \\
\text { estado creadora }\end{array}$ & $\begin{array}{l}\text { Federal } \\
\text { Estatal } \\
\text { Municipal }\end{array}$ & $\begin{array}{l}\text { Nacional } \\
\text { Departamental } \\
\text { Distrital } \\
\text { Municipal }\end{array}$ \\
\hline $\begin{array}{l}\text { Por organismo } \\
\text { creador }\end{array}$ & $\begin{array}{l}\text { Gobierno } \\
\text { Entidad o dependencia de gobierno } \\
\text { Organización privada }\end{array}$ & $\begin{array}{l}\text { Gobierno } \\
\text { Cajas de compensación familiar } \\
\text { Cooperativas } \\
\text { Fundaciones } \\
\text { Comunidad de los barrios }\end{array}$ \\
\hline Por función & $\begin{array}{l}\text { Bibliotecas centrales } \\
\text { Bibliotecas regionales } \\
\text { Bibliotecas municipales }\end{array}$ & $\begin{array}{l}\text { Bibliotecas públicas } \\
\text { Bibliotecas populares }\end{array}$ \\
& $\begin{array}{l}\text { Red Nacional de Bibliotecas Públicas } \\
\text { (1983) } \\
\text { Redes Estatales (1983), bajo el control de } \\
\text { 32 coordinadores estatales } \\
\text { Redes Municipales (1983) }\end{array}$ & $\begin{array}{l}\text { Red Departamental de Bibliotecas Públicas } \\
\text { de Antioquia (1972) } \\
\text { Red Colombiana de Bibliotecas Públicas } \\
\text { (1978), con 30 coordinaciones departa- } \\
\text { mentales, que a partir del año 2000 pasó a } \\
\text { ser la Red Nacional de Bibliotecas Públicas } \\
\text { Red de Bibliotecas Público-Escolares del } \\
\text { municipio de Medellín (1984) }\end{array}$ \\
\hline
\end{tabular}

Fuente: Jeimy Hernández Toscano (2009).

En México las bibliotecas públicas son materia del gobierno, el cual invita a incorporarse dentro de la Red Nacional a todos las iniciativas en la materia que realizan los sectores privado y social. Por su parte, Colombia muestra otro panorama, en donde los esfuerzos de los sectores social y privado tienen un alcance y reconocimiento amplio. 


\section{COMPARATIVO DE ESTADÍSTICAS E INDICADORES GENERADOS}

En ambas redes nacionales se trabajan estadísticas que coinciden en proporcionar datos sobre:

- La cantidad de usuarios registrados o afiliados.

- La cantidad de asistentes diaria /o mensual.

- La cantidad de usuarios que utilizaron los equipos de cómputo.

- La cantidad de préstamos a domicilio.

En Colombia también se levanta información sobre la cantidad de préstamos en sala y se consigna el reporte de las actividades dirigidas a grupos específicos de la comunidad. El formato de registro estadístico de México incluye la cantidad de actividades de fomento a la lectura, así como el número de asistentes; asimismo se pueden reportar actividades culturales o educativas realizadas en o por las bibliotecas públicas.

Un rasgo sobresaliente en materia de la información generada sobre la Red Nacional de Bibliotecas Públicas de Colombia está enunciado en su legislación, misma que contempla el establecimiento de un sistema de información que permite orientar las políticas, la planeación, el seguimiento y la evaluación de esta Red, así como de los planes nacionales de lectura y escritura. La creación y el mantenimiento de este sistema de información es función del Ministerio de Cultura. ${ }^{16}$

En México no se cuenta con un sistema de información parecido, aunque entre las atribuciones de la Secretaría de Educación Pública se ha considerado que puede llevar a cabo o patrocinar investigaciones encaminadas a fomentar el uso de los servicios bibliotecarios, así como el hábito de la lectura. ${ }^{17}$

Ambos países tienen indicadores de gestión para conocer los desarrollos de sus redes de bibliotecas públicas. En México los indicadores de gestión contemplados para el año 2011 eran los siguientes: ${ }^{18}$

- Materiales entregados a redes estatales.

- Instalación de bibliotecas modelo.

- Bibliotecarios certificados.

16 Decreto No. 2907 de 2010 por el cual se reglamenta parcialmente la ley 1379 de 2012 sobre la Red Nacional de Bibliotecas Públicas. Localizado: 2 sept. 2012, en: http://www.alcaldiabogota.gov. co/sisjur/normas/Norma1.jsp?i=40115. Cf. El artículo 32, párrafo 9.

17 Ley general de bibliotecas.. Localizado: 2 sept. 2012, en: http://www.diputados.gob.mx/LeyesBiblio/pdf/134.pdf. Cf. artículo 7, párrafo 15.

18 Información proporcionada en la Dirección General de Bibliotecas del Consejo Nacional para la Cultura y las Artes de México. 
- Bibliotecas públicas con módulos de servicios digitales distribuidos.

- Recursos digitales en servicio.

- Actividades culturales y de fomento a la lectura en la Biblioteca de México "José Vasconcelos" y en la Biblioteca Vasconcelos. ${ }^{19}$

- Asistentes a las actividades culturales y de fomento a la lectura en la Biblioteca de México "José Vasconcelos" y en la Biblioteca Vasconcelos.

- Usuarios atendidos en la Biblioteca de México "José Vasconcelos" y en la Biblioteca Vasconcelos.

- Atención a personas con discapacidad en la Biblioteca de México "José Vasconcelos" y en la Biblioteca Vasconcelos.

- Visitantes a la página web de la Dirección General de Bibliotecas, la Biblioteca de México "José Vasconcelos" y la Biblioteca Vasconcelos.

Los 44 indicadores definidos para la Red Nacional de Bibliotecas Públicas de Colombia son de carácter básico y complementario, y fueron definidos para informar sobre los variados componentes del quehacer bibliotecario que se requiere conocer para emprender tareas de planeación o de diseño de políticas. En la Tabla 3 mostramos la conformación general de este sistema de indicadores: ${ }^{20}$

Tabla 3

\begin{tabular}{|l|c|c|c|}
\hline \multicolumn{1}{|c|}{ Tema } & Básicos & Complementarios & Total \\
\hline Usuarios & 3 & 2 & 5 \\
\hline Préstamos & 2 & - & 2 \\
\hline Consultas & - & 1 & 1 \\
\hline Actividades & 1 & 11 & 12 \\
\hline Horario & 1 & - & 1 \\
\hline Fondos & 4 & 4 & 8 \\
\hline Audiovisuales & - & 1 & 1 \\
\hline Infraestructura & 4 & - & 4 \\
\hline Personal & 1 & 2 & 3 \\
\hline Presupuesto & 3 & 4 & 7 \\
\hline Total & 19 & 25 & 44 \\
\hline
\end{tabular}

Conforme este esquema, tenemos, por ejemplo, los siguientes indicadores de usuarios:

19 Estas dos bibliotecas son las únicas que forman parte de la estructura del gobierno federal, y la primera es contemplada en la legislación mexicana como cabeza de la Red Nacional de Bibliotecas Públicas.

20 Tabla realizada a partir de la información de Ministerio de Cultura de Colombia. Biblioteca Nacional (2009). 
- Usuarios atendidos por habitante: Es la proporción de habitantes que son atendidos en la biblioteca.

- Usuarios atendidos sobre la capacidad de la sala de lectura: es la proporción del espacio disponible para los usuarios.

- Usuarios afiliados a la biblioteca por habitante: es la proporción de habitantes que están afiliados a la biblioteca.

- Usuarios de Internet sobre capacidad de salas de Internet: es la proporción del espacio disponible en las salas de Internet para los usuarios.

- Usuarios de videoteca/sonoteca sobre capacidad videoteca/sonoteca: es la proporción del espacio disponible en los espacios de videoteca/ sonoteca para los usuarios.

Podemos notar que los indicadores mexicanos son más generales y apuntan a aspectos centrados en los resultados, además de que varios de ellos reportan datos sobre las bibliotecas que están bajo la responsabilidad del gobierno federal. En tanto los indicadores de las bibliotecas públicas colombianas son más operativos, y los datos que pueden aportar están más enfocados para servir en la planeación y el diseño de políticas.

\section{Propuesta de indicadores de Gestión}

En materia de indicadores de bibliotecas públicas debemos notar que desde el año 2002 se propuso realizar un esquema de indicadores mínimos para el Programa Iberoamericano de Cooperación en Bibliotecas Públicas (PICBIP). Se propuso que para su realización se debían considerar las normas ISO 11620-1998 (Indicadores de gestión para bibliotecas) e ISO 2789-1991 (Estadísticas internacionales de bibliotecas) así como las directivas para indicadores de IFLA/2001. ${ }^{21}$ En este marco se planteó la necesidad de realizar las siguientes actividades:

1) Construir consensos para la creación del sistema sobre la base de un análisis profundo en términos políticos y técnicos de los sentidos y alcances del mismo. El análisis de cada uno de los países sobre los elementos

21 Cf. Programa Iberoamericano de Cooperación en Bibliotecas Públicas (2002), Sistema de indicadores mínimos para bibliotecas públicas de Iberoamérica, Documento de trabajo presentado en el III Encuentro Iberoamericano de Responsables Nacionales de Bibliotecas Públicas, Cartagena de Indias, Colombia, 26-28 nov. 2002, Madrid: Ministerio de Educación, Cultura y Deporte, Subdirección General de Coordinación Bibliotecaria, pp. 55-62. 
propuestos en este documento debería llevar lo más pronto posible a contar con las ideas, reacciones y sugerencias de cada uno.

2) Asimismo, sería necesario realizar un estudio para analizar los procesos y sistemas de evaluación de los países de la región en materia de gestión de bibliotecas públicas, tanto en sus aspectos conceptuales y políticos, como en sus desarrollos técnicos. Dicho estudio arrojaría la información necesaria para identificar el nivel de consolidación de las condiciones requeridas para el diseño e implementación del sistema de indicadores.

3) Como resultado de las dos anteriores tareas se estaría en condiciones para formular una propuesta técnica y económica para desarrollar un proyecto específico con el objetivo de diseñar e implementar el sistema de indicadores.

$\mathrm{Al}$ año siguiente de la anterior propuesta se llevó a cabo un taller de evaluación bibliotecaria en Cartagena de Indias, Colombia, que puso un fuerte acento en la cuestión de los indicadores, definiendo los diversos tipos que se pueden utilizar, así como los componentes de un sistema de indicadores. ${ }^{22}$

A una década de estas propuestas se sigue trabajando en ellas y no se han reportado los avances, por lo que se requiere indagar más sobre el alcance e impacto de estas acciones.

\section{CONCLUSIONES Y RECOMENDACIONES}

Las bibliotecas públicas de México y Colombia muestran diferencias en su concepción, organización y operación, que son resultado de las distinciones de su división política territorial, así como por la forma como se han desarrollado las bibliotecas públicas. Ello con mayor injerencia de los gobiernos en México y como resultado de la acción social y de particulares en Colombia.

A pesar de que este estudio comparativo evidencia modelos bibliotecarios diferenciados entre los dos países, hemos podido notar que hace una década se propuso en el Programa Iberoamericano antes mencionado (PICBIP) la construcción de indicadores mínimos que se pudieran compartir entre los países iberoamericanos, con la finalidad de coadyuvar a la mejora de la gestión de las bibliotecas públicas. 
En este sentido los indicadores de gestión deben reportar datos de interés y con determinado valor para mantenernos informados sobre el estado de las bibliotecas públicas, además de servir para la toma de decisiones al momento de la planeación o el diseño de políticas, así como para contrastar el desarrollo de las operaciones.

Estos indicadores de gestión pueden enfocarse a varios temas, sobre todo a los que se consideren de mayor importancia o sobre los que correspondan a situaciones que se deseen cambiar o para resolver algún problema que se haya detectado. $\mathrm{O}$ bien, en su caso, para medir el impacto social de algún servicio bibliotecario. Así, por ejemplo, tendríamos datos para la comprensión de la rotación del personal en las bibliotecas públicas mexicanas, o sobre el estado de las colecciones en las bibliotecas públicas colombianas.

Recomendamos ampliamente la continuación de esta investigación en las siguientes líneas:

- Comparación a mayor profundidad de los modelos bibliotecarios públicos de ambos países.

- Comparación a mayor profundidad del estado de los acervos, las tecnologías, los recursos humanos, las actividades culturales y recreativas, el financiamiento, los presupuestos y la infraestructura de las bibliotecas públicas de ambos países.

- Comparación a mayor profundidad de las normativas operativas que se llevan en las bibliotecas públicas de ambos países.

- Propuesta de un sistema de información para las bibliotecas públicas de México, basado en el desarrollo del sistema homólogo colombiano.

- Diseño de un sistema de indicadores mínimos de gestión para las bibliotecas públicas de ambos países.

- Análisis de las diferentes variables de impacto social y su vínculo con las bibliotecas públicas.

\section{BiBLIOGRAFÍA}

Álvarez Zapata, Didier (1993), "Productividad y misión de la biblioteca pública latinoamericana”, en El libro en América Latina y el Caribe, 75 , pp. 35-39.

Álvarez Zapata Didier y Gómez García, J. G. (2002), "El discurso bibliotecario público sobre la lectura en América Latina, 19502000: Una revisión preliminar con énfasis en Colombia”, en Revista interamericana de bibliotecología, 25(1), pp. 11-36. 
Betancur Betancur, Adriana María (1997), Biblioteca pública y democracia, Bogotá, DC: Fundalectura, Colcultura, Comfenalco. 60 p.

Castrillón, Silvia (1999), "Las bibliotecas públicas y escolares y la lectura” en El libro en América Latina y el Caribe, 87, pp. 39-51.

Colombia, Ley No. 1379 por la cual se organiza la Red Nacional de Bibliotecas Públicas..., localizado el 2 sept. 2012, en: http://www.ascolbi.org/documentos/Ley_1379_2010_Bibliotecas.pdf

Real Academia Española (2001), Diccionario de la Lengua Española. $22^{a}$ ed., localizado el 2 sept. 2012, en: http://lema.rae.es/drae/?val $=$ comparaci $\% \mathrm{C} 3 \% \mathrm{~B} 3 \mathrm{n}$

Declaración de Caracas sobre la biblioteca pública como factor de desarrollo e instrumento de cambio social en América Latina y el Caribe (1994). Hojas de lectura, 26, pp. 4-6.

Domínguez Sanjurjo, Ramona y García de Paso Gómez, Esperanza (2003), La evaluación en la biblioteca pública: Indicadores y otros elementos de control, localizado: 2 sept. 2012, en: http://www.sinic.gov.co/SINIC/Publicaciones/Archivos/127-2-3-17-2006711104020.pdf

Gill, Philip (2007), Directrices IFLA/Unesco para el desarrollo del servicio de bibliotecas públicas, $2^{a}$ ed. México: CNCA/DGB. 220 p.

Hernández Pacheco, Federico (2011), La Biblioteca Vasconcelos: un nuevo modelo de biblioteca pública en México, Trabajo presentado en el $7^{\circ}$ Seminario Hispanomexicano en Biblioteconomía y Documentación. México: UNAM, CUIB, disponible en: http://cuib.unam. $\mathrm{mx} /$

Hernández Toscano, Jeimy (2009), La Red Nacional de Bibliotecas Públicas. 6 h. localizado: el 2 sept. 2012, en: http://www.cerlalc.org/redplanes/boletin_redplanes2/imagenes/documentos/2_Red_bibliotecas. pdf

Jaramillo, Orlanda et al. (2005), La biblioteca pública: Una mirada desde su génesis y desarrollo, Medellín: Universidad de Atioquia, EIB, CICInf. 140 p.

Jaramillo, Orlanda et al. (Comp.) (2005), Biblioteca pública y lectura pública, Medellín: Universidad de Antioquia, EIB, CICInf. 195 p.

Jaramillo, Orlanda y Montoya Ríos, Mónica (2000), "Revisión conceptual de la biblioteca pública", en Revista interamericana de bibliotecología, 23(1/2), pp. 13-56.

Jaramillo, Orlanda, Montoya R., Mónica y Gómez L., Biviana (2002), "La biblioteca pública popular: Cuatro experiencias de desarrollo", en Revista interamericana de bibliotecología, 25(1), pp. 37-63.

Jaramillo, Orlanda, Montoya Ríos, Mónica y Uribe Tirado, Alejandro (2008), Biblioteca Pública: su gestión en el contexto de la sociedad de la información, Buenos Aires: Alfagrama. 190 p.

Martínez González, Jerónimo (1999), "La biblioteca pública en la comunidad iberoamericana" en El libro en América Latina y el Caribe, 87, pp. 8-21. 
México, Ley general de bibliotecas, localizado el 2 sept. 2012, en: http://www.diputados.gob.mx/LeyesBiblio/pdf/134.pdf.

Milanesi, Luis (1993), “¿Bibliotecas o centros de cultura?”, en El libro en América Latina y el Caribe, 75, pp. 44-49.

Ministerio de Cultura de Colombia Biblioteca Nacional (2009), Sistema de indicadores de gestión para bibliotecas públicas de Colombia, localizado el 2 sept. 2012, en: http://snb.bnp.gob.pe/snb/index. php?option $=$ com_ content $\&$ view $=$ section $\&$ layout $=$ blog $\&$ id $=7 \&$ Itemid=2

Montoya Ríos, Mónica, Jaramillo, Orlanda y Moncada Patiño, José Daniel (2007), "Un reconocimiento de los actores de la biblioteca pública en Antioquia”, en Revista interamericana de bibliotecología, 30(2), pp. 205-227.

Oliver, Victoria (s. d.), El papel de las bibliotecas en los sistemas nacionales de información científica, localizado el 2 sept. 2012, en: http:// dialnet.unirioja. es/servlet/fichero_articulo?codigo=967403

Olivera, Lahore, Carlos (1986), Introducción a la educación comparada, San José: Universidad Estatal a Distancia. 484 p.

Parada, Alejandro. E. (2011), "La reunión del CERLALC y la contribución de las bibliotecas públicas como agentes del desarrollo: Paipa, Boyacá, Colombia”, en Información, cultura y sociedad, 25, pp. 153-158.

Programa Iberoamericano de Cooperación en Bibliotecas Públicas (2002), Sistema de indicadores mínimos para bibliotecas públicas de Iberoamérica, Documento de trabajo presentado en el III Encuentro Iberoamericano de Responsables Nacionales de Bibliotecas Públicas, Cartagena de Indias, Colombia, 26-28 nov. 2002, Madrid, Ministerio de Educación, Cultura y Deporte, Subdirección General de Coordinación Bibliotecaria, pp. 55-62

Santos, María Josefa, et al. Disminuyendo la brecha digital: el nuevo papel de la biblioteca pública mexicana. México: Universidad Nacional Autónoma de México: Consejo Nacional para la cultura y las Artes, 2012. 170 p. 
